\title{
SAFEGUARDING VULNERABLE ADULTS
}

\author{
- $\quad$ World Elder-Abuse Day Friday 15 June 2018 \\ - Safeguarding Vulnerable Adults - The National Safeguarding Committee
}

\section{WORLD ELDER ABUSE AWARENESS DAY - FRIDAY 15 JUNE 2018}

The International Network for the Prevention of Elder Abuse (INPEA) first championed World Elder Abuse Awareness Day in 2006 in order to bring attention to the issue of elder abuse in our global society.

World Elder Abuse Awareness Day, held on June 15 each year, is in support of the United Nations International Plan of Action which recognises the significance of elder abuse as a public health and human rights concern. The day serves as a call to action for individuals, organisations and communities to raise awareness about abuse, neglect and the exploitation of older people.

The detection and response to elder abuse is significantly challenged by the lack of awareness and understanding, or even recognition of the issue among our communities

Elder Abuse is defined as 'a single or repeated act, or lack of appropriate action, occurring within any relationship where there is an expectation of trust which causes harm or distress to an older person or violates their human and civil rights.' (Protecting our Future, Report of the Working Group on Elder Abuse, September 2002). Sixty five years of age is taken as the point beyond which abuse may be considered to be elder abuse.

World Elder Abuse Awareness Day provides an opportunity for all of us to focus our attention on elder abuse. It challenges each one of us to help eradicate abuse of older people and to redouble efforts to promote respect and dignity for all older people. Everybody has a role to play and the challenges posed by elder abuse cannot be met solely by any one individual, organisation, or state body.

\section{Types of Elder Abuse}

The different types of abuse may be categorised as follows:-

- Psychological abuse including emotional abuse, threats of harm or abandonment, deprivation of contact, humiliation, blaming, controlling, intimidation, coercion, harassment, verbal abuse, isolation or withdrawal from services or supportive networks.

- Physical abuse - including slapping, pushing, hitting, kicking, misuse of medication, inappropriate restraint (including physical and chemical restraint) or sanctions.

- Financial or material abuse including theft; fraud; exploitation; pressure in connection with wills, property or inheritance, or financial transactions; or the misuse or misappropriation of property, possessions or benefits.

- Neglect (including self-neglect) and acts of omission including ignoring medical or physical care needs, the withholding of the necessities of life, such as medication, adequate nutrition and heating.

- Discriminatory abuse including ageism, racism, sexism, that based on a person's disability, and other forms of harassment, slurs or similar treatment.

- Institutional abuse may occur within residential care and acute settings including nursing homes, acute hospitals and any other in-patient settings, and may involve poor standards of care, rigid routines and inadequate responses to complex needs.

- Sexual abuse including rape and sexual assault or sexual acts to which the older adult has not consented, or could not consent, or into which he or she was compelled to consent. 
Any person or organisation may be guilty of abuse. Most often it is someone well known to the older person, for example, a family member, relative, friend or care provider - a relationship where there is an expectation of trust.

Abuse can take place anywhere: most abuse takes place in the home, whether the person is living alone or with family. It may also occur within residential, day-care, or hospital settings, other places assumed to be safe, or in a public place.

\title{
If you or someone you know is being abused, talk to
}

- Someone you trust

- Your health professional - your family doctor, public health nurse, HSE Social Worker (Senior Case Worker) or anyone at your local health centre

- Your local Garda Station

- The HSE Information Line on 185024 1850, Monday to Saturday 8am to 8pm (they will give you details of HSE staff in your local area who can help you)

- Your bank or solicitor

- General managers in your HSE Local Health Office

- Nursing home owner or the nurse in charge

\section{Reporting abuse:}

\section{The Health Service Executive}

The HSE is the competent authority for the reporting of Elder Abuse and has a dedicated Elder Abuse Service. For more information, see the Safeguarding section of the HSE's website which provides details of the Safeguarding policy, together with elder abuse publications. Please see also the details of the HSE Safeguarding and Protection Teams which are located in each of the Community Health Care Organisations.

You can also seek advice from the HSE Information Line:

Monday to Saturday, $8 \mathrm{am}-8 \mathrm{pm}$

Call Save: 1850241850

Email: info@hse.ie

\section{Department of Social Protection}

The Department will also act on any reports it receives of alleged abuse of its pension/benefit recipients, consulting or involving as appropriate other relevant agencies such as the HSE or An Garda Siochána. Investigations of alleged abuse are coordinated by a nominated officer in the Department:

\author{
Martin Keville \\ Assistant Principal Officer \\ State pension non-contributory \\ Department of Employment Affairs and Social Protection \\ College Road, Sligo, Ireland. \\ Tel: 00353-71-9193260 (direct) \\ Email: martin.keville@welfare.ie
}




\section{SAFEGUARDING VULNERABLE ADULTS (AGED 18 AND OVER) THE NATIONAL SAFEGUARDING COMMITTEE:}

In December, 2014, the Health Service Executive published its Policy Safeguarding Vulnerable Persons at Risk of Abuse - National Policy and Procedures which encompasses both elder abuse, and concerns of abuse relating to people availing of disability services. One of the structures involved in furthering the safeguarding policy and agenda is the National Safeguarding Committee, which is a multi-agency committee and inter-sectoral body. The NSC published its Strategic Plan 2017-2021 in November 2016, followed by the Adult Safeguarding Bill 2017 in May of this year.

The National Safeguarding Committee, on which the Department is represented, has four main objectives:

- Raising public awareness and understanding;

- Supporting and promoting the protection of people's rights

- Informing and influencing Government Policy and

- Building the Committee's capacity and capability.

\section{Health Service Executive Safeguarding Teams:}

The Safeguarding section of the HSE's website provides details of the NSC's policy, together with elder abuse publications. Please see also the details of the HSE Safeguarding and Protection Teams which are located in each of the Community Health Care Organisations.

\section{Irish Research Findings:}

Recent research shows that half of all Irish adults say they have experienced the abuse of vulnerable adults either through being abused themselves or through seeing somebody close to them abused. The research, commissioned by the National Safeguarding Committee and conducted over the period 5-7 December 2016, indicates widespread public concern that many vulnerable adults are open to and are experiencing physical, emotional, psychological and financial abuse.

Among the research findings are:

- $\quad$ Physical abuse of vulnerable adults has been witnessed/suspected by 1 in 3 adults, very often in the home.

- Over 1 in 3 has experienced emotional abuse.

- Almost 2 in 5 (38\%) think vulnerable adults are badly treated. One in three believes vulnerable adult abuse to be widespread.

- There is significant public concern about the need to safeguard those who are limited in their ability to protect themselves.

- $\quad$ There is a lack of clarity over where to report vulnerable adult maltreatment, particularly among the young

Adults who may be vulnerable are those who may be restricted in their capacity to guard themselves against harm or exploitation, possibly as a result of illness, dementia, mental health problems, physical disability or intellectual disability. 


\section{Department of Employment Affairs and Social Protection Working Group on Agents and Safeguarding Vulnerable Adults:}

A Working Group has been established in the Department to examine and make recommendations on the adequacy of the current procedures and processes for..

- appointing 'agents' for social welfare payments

- reviewing existing agent arrangements and legislation

- dealing with specific complaints regarding named agents when they arise (with the involvement of relevant external agencies as necessary)

- continuing to raise the awareness of staff on safeguarding and protection of vulnerable adults, with a particular emphasis on financial abuse.

The Group will also assess the implications for processes and procedures for agent arrangements in the context of the Assisted Decision-Making (Capacity) Act 2015 and the Codes of Practice being developed by the National Disability Authority under the Act, and will make recommendations for changes necessary in order for the Department to comply with that legislation.

\section{Current provisions for Payment Agents and the responsibilities of an Agent:}

\section{Persons who can be appointed Agent}

- A family member

- A person who has been appointed to be a care representative of the customer;

- Where the customer is resident in a care centre for a continuous period of four weeks or more, and where no other suitable person is available and willing to be appointed, a representative of the care centre may be appointed to act as agent.

- (For a Type 2 Agent) a person, other than the medical practitioner who signed the form, who appears to the Department to have a good and sufficient interest in the welfare of the customer.

\section{Temporary Agent}

A temporary agent can be appointed for a short period of time, may only collect up to five payments in a six month period, where a person is unable to collect their payment at a post office. A "Temporary Agent" form, which is only available at the post office, should be completed by the customer. When collecting the payment the agent should present this form along with the customers' social services card or public services card at the post office.

\section{'Type 1' Agent - An Agent authorised by the pension/benefit recipient to collect and deliver to them their weekly payment}

Where a customer is unable to collect their payment at the post office, for example due to an illness or loss of mobility, they can nominate a person to collect the payment on their behalf. The customer must complete a form and a notification is then sent to the customer and arrangements are made with the post office to facilitate the agent collecting the payment. When the payment is collected by the agent he or she must give the customer the full amount. The person nominated to act as agent must be over 18 years. If the customer is resident in a nursing home they may nominate the person 
in charge of the nursing home to collect the payment on their behalf. The customer may cancel or revoke an agent arrangement at any time and appoint another agent.

\section{'Type 2' Agent - Where the pension/benefit recipient is unable to manage their own financial affairs}

Where a customer is unable to manage their own financial affairs an agent may be appointed to collect the payment and act on behalf of the claimant or beneficiary. It is recommended that a separate account be set up for this purpose and that the Agent carefully maintain records and receipts of all discharges and transactions made on behalf of the pension/benefit recipient.

In all cases a medical practitioner must certify that the customer is unable for the time being to manage his or her own financial affairs for reasons which may include one of the following:

- inability to understand the basis of possible entitlements to benefit;

- inability to understand and complete the claim form;

- inability to understand and deal with correspondence and enquiries concerning the claim;

- inability to manage benefit payments received.

An Agent (Type 2) is responsible for ensuring that:

- the payment is used for the benefit of the customer;

- monies are not spent on items or services that the customer has an entitlement to and are available;

- The payment is lodged to an interest bearing account for the benefit of the customer;

- any changes in the customer's circumstances are reported to the Department.

- The agent must also keep a record of all sums received and all transactions made in relation to the benefit payment, and produce the records if requested to do so by the customer, his or her nearest relative, or an officer of the Department.

- The Department may cancel an agent arrangement at any time where it has reason to believe that the arrangement is not working satisfactorily or that the payment is not being used for the benefit of the customer. If this occurs, the agent must, where appropriate, return the payments on request.

\section{Ward of Court or Power of Attorney}

In the case of a ward of court or a person appointed under an enduring power of attorney, the Department will make payments directly to the Committee of the Ward or to the Attorney by nominating the Committee or the Attorney as agent for the social welfare customer. All such payments will be made electronically to a nominated bank account.

\section{Health Service Executive}

Where the customer is resident in a care centre under the management of the Health Service Executive (HSE) for a continuous period of four weeks or more and wishes to have a representative of the care centre appointed to act as their agent, the customer or their representative should contact the manager of the care centre to put the arrangement in place.

\section{Other useful websites/resources:}

The National Centre for the Protection of Older People http://ncpop.ie/ and its research report Financial Abuse of Older People: A Review

Keep Control : Safeguarding your Finances in Later Life provides useful information to help understand the challenges faced by people as they age, and to empower them to take preventative steps. 
MK - 5/2018. 